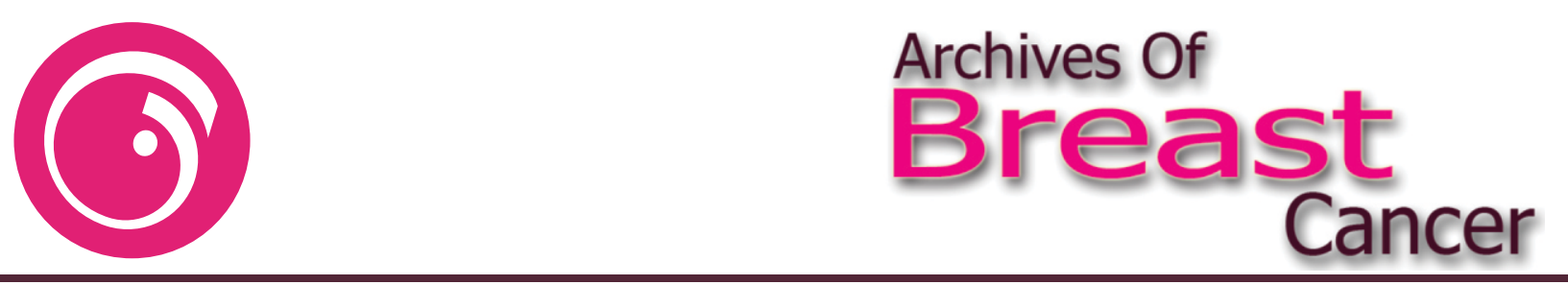

DOI: $10.32768 / a b c .201854150-158$

\title{
Displaced Epithelium in Breast Pathology: A Review
}

\author{
Behnaz Jahanbin ${ }^{a}$, Vahid Soleimani ${ }^{a}$, Farid Azmoudeh-Ardalan*a \\ ${ }^{a}$ Pathology Department, Cancer Institute, Tehran University of Medical Sciences (TUMS), Tehran, Iran
}

ARTICLE INFO
Received:
03 September 2018
Revised:
22 September 2018
Accepted:
29 September 2018


Key words:
Breast,
displaced epithelium,
iatrogenic,
histopathology

\begin{abstract}
Background: Although iatrogenic displacement of epithelial cells after breast instrumentation is a well-documented phenomenon, it is usually underdiagnosed. Misinterpretation of this issue results in overtreatment of patients in some instances. Additionally, the hazard of tumor seeding and dissemination after needling is a concern to both clinicians and patients. Both issues are addressed in this narrative review.

Methods: We searched PubMed for abstracts of English-language publications using keywords "needle track/tract" and "displaced epithelium/epithelial displacement/iatrogenic displacement," which resulted in 439 records restricted to human subjects. We read all the abstracts and selected 27 manuscripts with the most relevance.

Results: There are some histopathologic features that can be useful in differentiating between epithelial displacement and real invasion/metastasis. The risk of seeding or metastasis after needling is shown to be trivial. Factors militating against the growth of dislodged cells are also discussed.

Conclusion: Epithelial displacement is an important issue in breast pathology that should be considered in every patient with a history of breast instrumentation.
\end{abstract}

\section{Introduction}

Displacement of tissue may occur following any type of intervention or surgical procedure in different organs. Both epithelial and mesenchymal components can be displaced. Implantation of carcinoma cells in the needle tract during percutaneous biopsy has been reported in cancers such as renal cell carcinoma, thyroid carcinoma, hepatocellular carcinoma, small cell carcinoma of lung and breast carcinoma. ${ }^{1-7}$

In breast tissue, displacement of epithelial component, both benign and malignant, may result in a misdiagnosis of invasive carcinoma or metastasis. Therefore, pathologists and other practitioners in the field of breast diseases should be cognizant of this phenomenon.

\author{
Address for correspondence: \\ Farid Azmoudeh-Ardalan, MD \\ Address: Pathology Department, Cancer Institute, Imam Khomeini \\ Hospital Complex, Tehran 14197-33141, Iran \\ Tel: +98 2161192502 \\ Fax: +98 2166923557 \\ e-mail: azmoudeh@tums.ac.ir
}

Displacement of epithelium is common after needling procedures, including percutaneous core needle biopsy that is commonly used for evaluation of suspected breast lesions. ${ }^{8-11}$ It occurs in any type of breast lesion. ${ }^{12}$ In one study, 22 out of 64 excised breast specimens showed displaced neoplastic cells in needle tracks. ${ }^{13}$ In a recent systematic review, displacement rate in a total of 927 cases from nine studies on surgically excised breast specimens ranged from $2 \%$ to $63 \%$. ${ }^{13,14}$ This wide range can be attributed to the type of breast lesion (more common in papillary lesions), time interval between needling and surgery, type of procedure, and needle gauge. Although both patients and clinicians may be concerned about the proliferation of displaced malignant cell resulting in tumor recurrence at needling site or distant organs, the risk of this socalled "seeding" is only $0.2 \%$ to $0.7 \%$. ${ }^{15-18}$

Epithelial displacement is important from two points of view including correct histopathologic diagnosis and hazard of needle track seeding or even metastasis. ${ }^{19}$ Therefore, both issues are addressed in this review. 


\section{Methods}

We searched PubMed for English-language publications related to human subjects using the following keywords: "needle track," "needle tract," "displaced epithelium," "epithelial displacement," and "iatrogenic displacement," which yielded 439 records. We read all the abstracts and selected 27 papers with the most relevance. ${ }^{1,2,5-7,12,13,15,17,20-37}$ The full texts of the selected papers were obtained. We used both the selected papers and our experience to write the narrative review. The images are all taken from our cases in the Cancer Institute of Tehran University of Medical Sciences.

\section{Results}

Definition of displaced epithelium and how it differs from real invasion or metastasis

When the epithelium is dislocated mechanically by surgical or radiological interventions, it is called displaced epithelium (DE). This iatrogenic phenomenon should be distinguished from local invasion or metastasis. In the latter situations, the neoplastic cells that have gained the ability to invade the stroma or vascular channels are dislodged from the main bulk of in situ carcinoma without requiring any external mechanical force. In both situations, some atypical cells are evident in the stroma, regional lymph nodes, or even distant sites such as bone marrow. Therefore, distinguishing between these two entities may be a great challenge for the histopathologist.

\section{Procedures resulting in $D E$}

Any type of instrumentation can result in DE, including fine needle aspiration, core needle biopsy, wire localization of lesions, vacuum-assisted breast biopsy (VABB), injections for sentinel lymph node identification, and incisional or excisional biopsies. ${ }^{22,37}$ $\mathrm{DE}$ has also been reported after liposuction in a male patient with gynecomastia. ${ }^{35}$

The least damaging method is fine needle aspiration, where a 22-G needle is employed for entering the tumor. Needles with a larger gauge, such as $11-$ or 14-G, used for tissue diagnosis, result in more frequent $\mathrm{DE}{ }^{38}$

Having a very low rate of false negative results, VABB has a sensitivity and specificity superior to core needle biopsy. ${ }^{23,39-41}$ In three studies, no malignant cell displacement was identified after this procedure. In these studies, 28,23 , and $21 \mathrm{VABBs}$ were performed using $11-\mathrm{G}, 14-\mathrm{G}$, and $11-\mathrm{G}$ needles, respectively. ${ }^{31,42,43}$

\section{Factors influencing the frequency of $D E$}

The number and volume of identified tumor cells in needle track is inversely related to the intervening time between core needle biopsy and excision of the lesion. ${ }^{22}$ Two main determinants of neoplastic cell displacement along needle tracks are the short term between core needle biopsy and excisional surgery and the histology of the tumor. ${ }^{38}$

In benign and malignant papillary lesions, epithelial displacement occurs more commonly in comparison with other neoplasms of the breast because of the fragility of these lesions. In one study in 2005,50 out of 53 cases with epithelial displacement had an underlying papillary lesion. ${ }^{27}$ These epithelia were dislocated to the stroma surrounding the papillary lesions and adjacent lymph-vascular channels imitating invasion. These displaced epithelia can be even transferred to axillary lymph nodes.

\section{Clinical significance of DE}

The trivial risk of development of clinical tumor recurrence at the needle biopsy site despite the high frequency of DE suggests that DE has little clinical significance. Radiotherapy is probably sufficient for eradicating isolated tumor cells in the needle track. The study of Boutin et al. on mesothelioma patients revealed metastasis in the needle track in 8 out of 20 patients who had not received radiation, while none of the twenty patients receiving radiotherapy developed metastasis. ${ }^{44}$ Thurfjell et al. showed local recurrence in $11 \%$ of patients with breast carcinoma who had undergone breast-conserving surgery $(33 / 303)$. Recurrence due to seeding in the needle track was suspected in 3 cases (3/33), none of whom had received postoperative radiotherapy. ${ }^{24}$ Therefore, radiation of breast tissue, which is often performed after lumpectomy, obviates the mentioned risk of local recurrence. Additionally, the needle track is often removed during the surgical excision of malignant tumors. ${ }^{32}$ A study on a large number of patients showed that core needle biopsy or fine-needle aspiration, for diagnosis of a malignant breast tumor, does not result in an increased risk of sentinel lymph node metastasis. ${ }^{45}$

The major issue is the risk of misinterpretation of DE by the pathologist who reviews the patient's excised material. ${ }^{30}$

\section{Histopathologic features of the needle track}

Displaced epithelia are most commonly identified at the site of needle track. The salient histopathologic features of needle track are as follows:

- Old or recent hemorrhage, depending on the interval between biopsy and excision (Figure 1).

-Hemosiderin deposition, either within the macrophages or in the stroma

-Granulation tissue formation, fibrosis, and chronic inflammation (Figure 2)

- Fat necrosis

- Foreign body reaction

- The presence of a large number of macrophages as identified by immunostaining for CD68 (Figure 3)

-The inflammation, hemorrhage, and fibrosis are arranged in a linear/elongated fashion (Figure 4) 


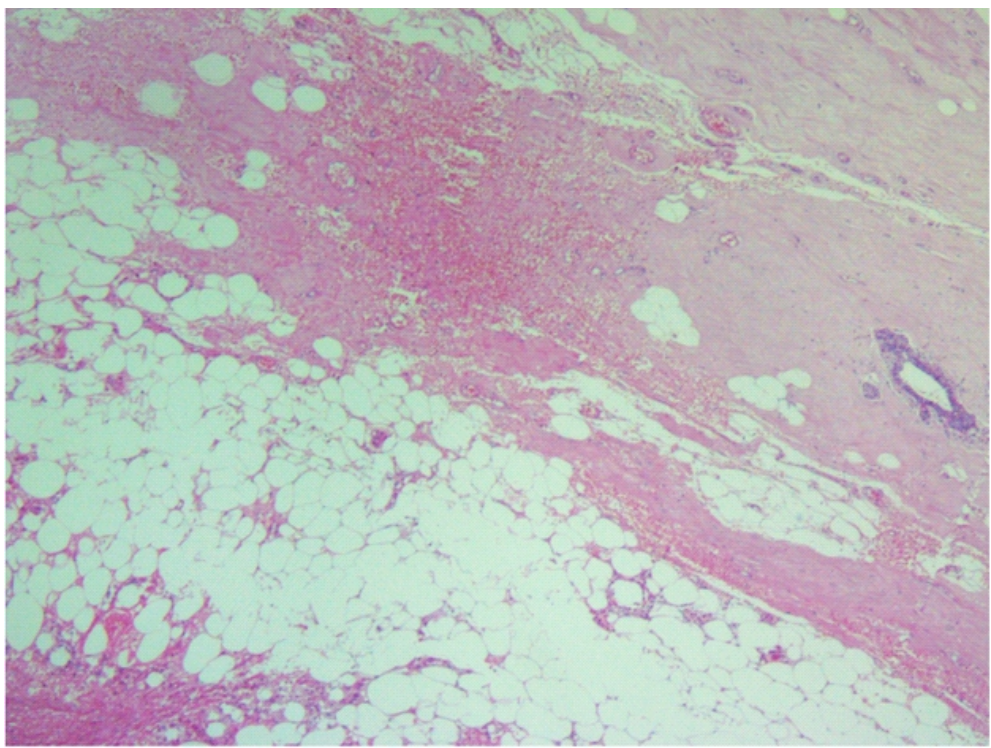

Figure 1. Hemorrhage at needling site $(\mathrm{H} \& \mathrm{E}, \times 40)$.

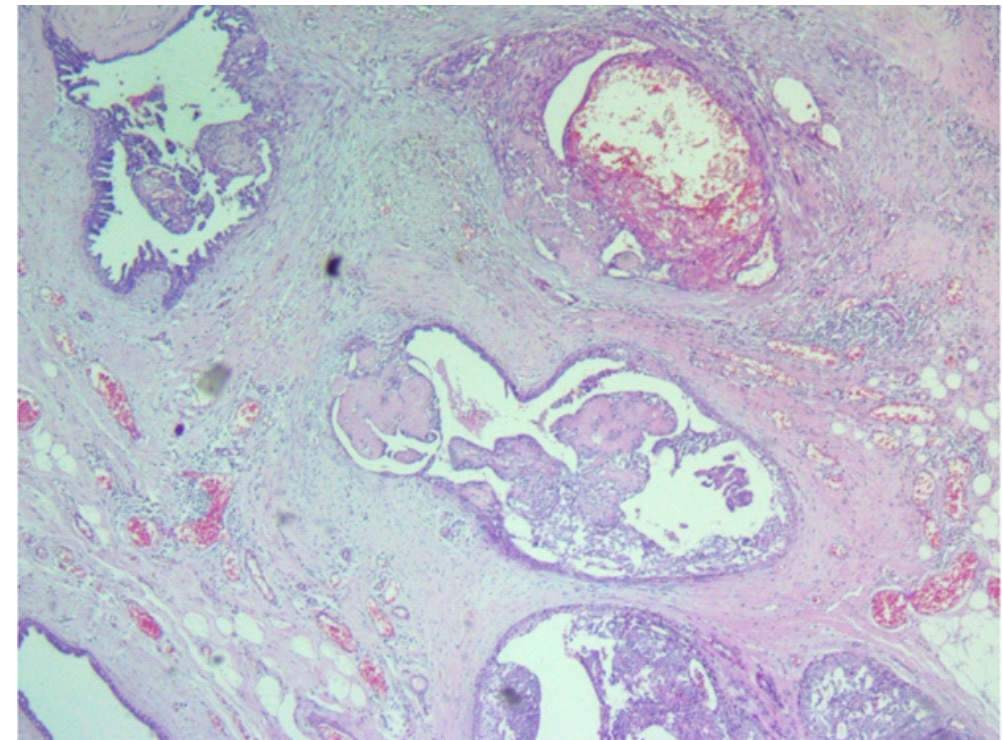

Figure 2. Intraductal papilloma with features of needle site. Note the hemorrhage, granulation tissue, and fibrosis $(\mathrm{H} \& \mathrm{E}, \times 40)$

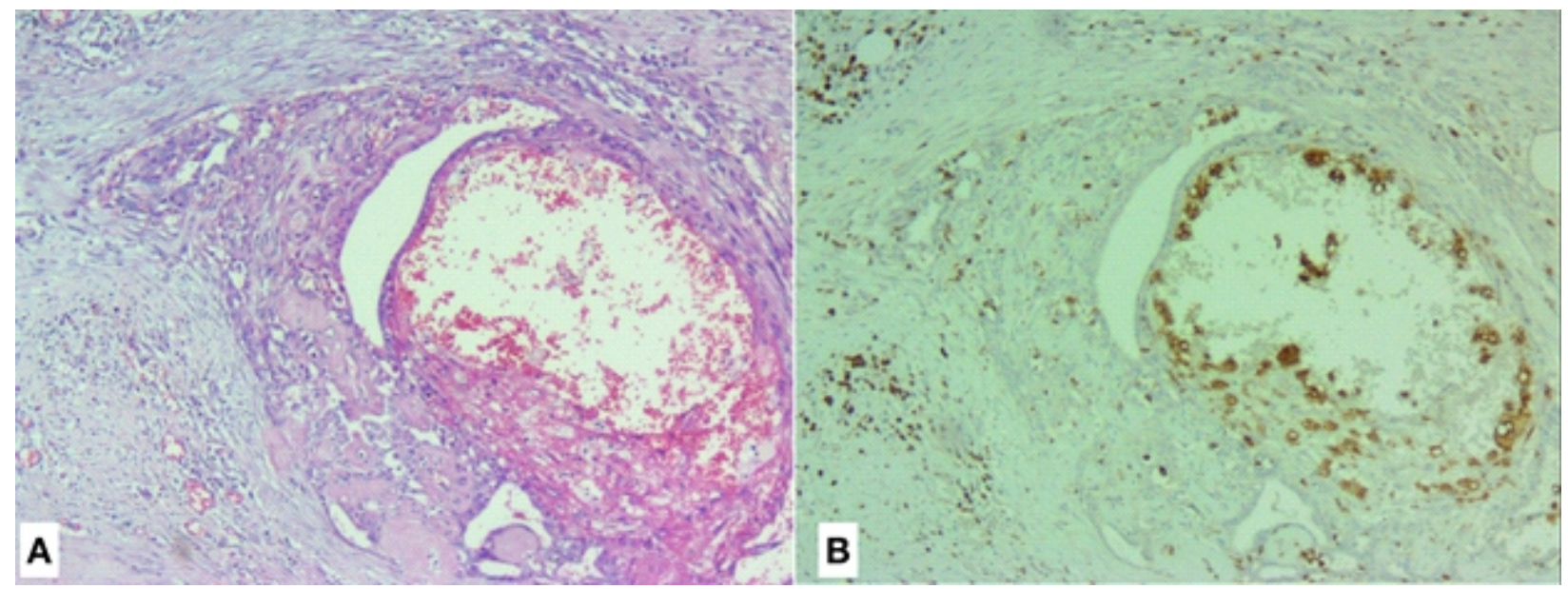

Figure 3. A. Intraductal papilloma in a case showing displaced epithelium. Note the hemorrhage at needle track site $(\mathrm{H} \& \mathrm{E}, \times 100)$; B. Immunostaining for CD68 highlights the macrophages at needling site $(\times 100)$. 


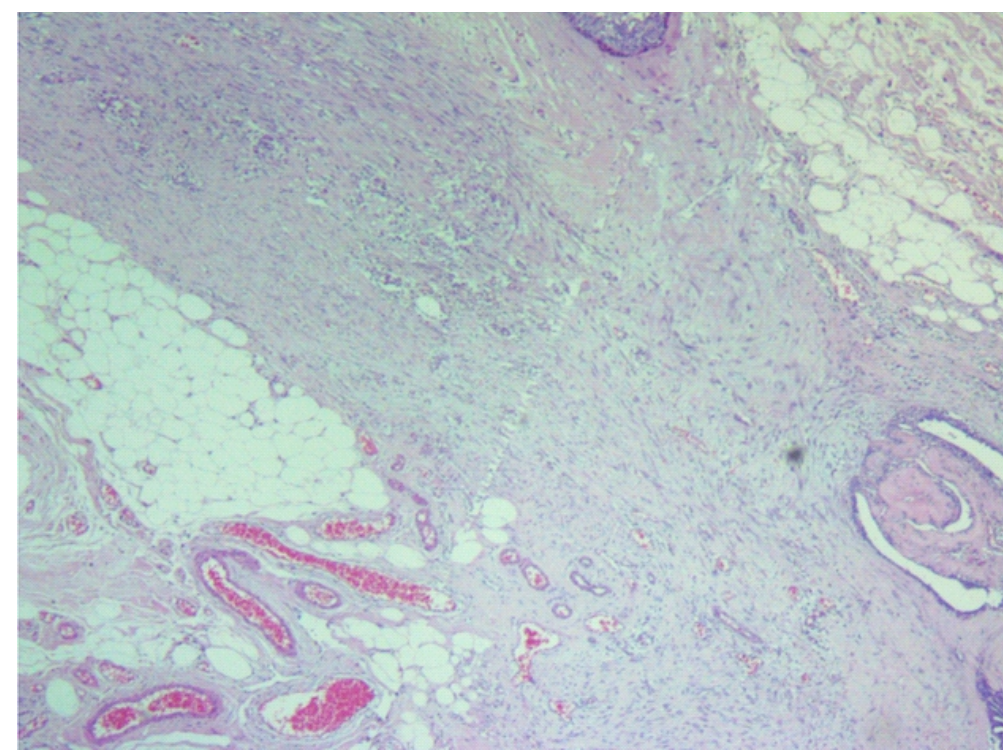

Figure 4. Needle track. A part of an intraductal papilloma is seen at the right side of the image. The elongated fibrosis and inflammation highlight the path of the needle biopsy performed a few weeks before $(\mathrm{H} \& \mathrm{E}, \times 40)$.

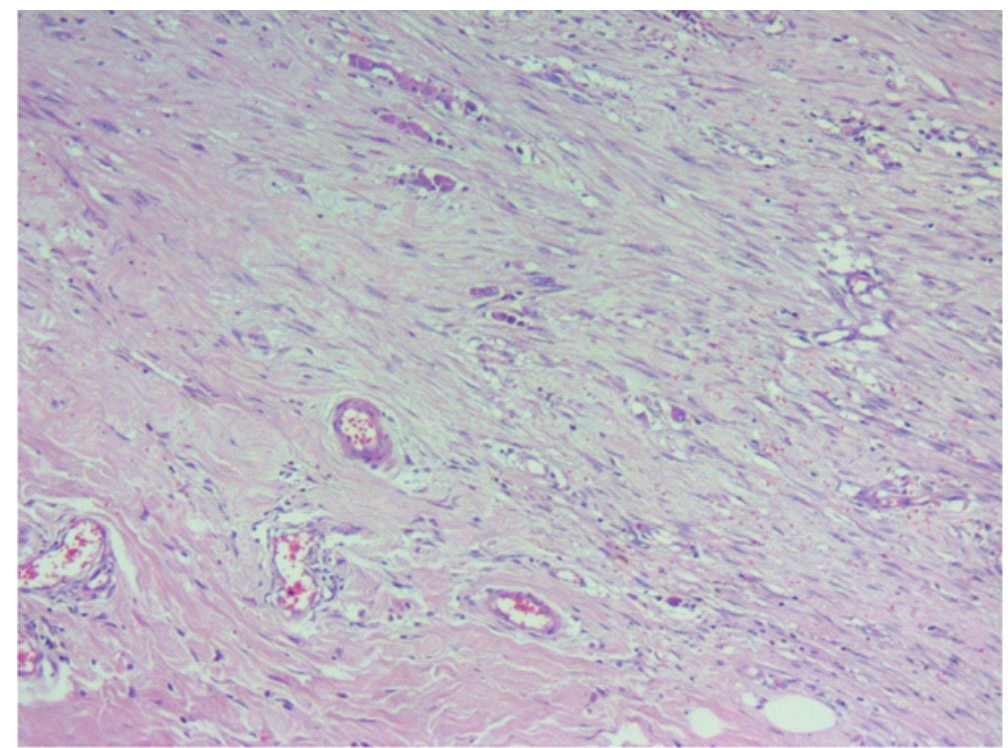

Figure 5. Displaced epithelium in a fibrotic stroma. Small cords or nests of displaced epithelium are evident in an extensively fibrotic stroma. The displaced epithelium is arranged in a rather linear fashion $(\mathrm{H} \& \mathrm{E}, \times 100)$.

Histopathologic features of DE and how it can be distinguished from authentic invasion or metastasis

DE should be suspected when we observe a major intraductal component (particularly if this component is a papillary proliferation) or a small presumably invasive tumor. ${ }^{27}$ The surgeon or radiologist should notify the pathologists, if there has been any history of prior biopsy or other instrumentations.

How can DE be differentiated from genuine invasive carcinoma? Apart from being located along needle track with aforementioned histopathologic features, the following characteristics may be helpful:

- The displaced epithelial cells are usually arranged in a linear pattern (Figure 5).

- The displaced cells show some degree of degeneration. It depends on the time interval between needling and excision. The longer this interval is, the more degenerative changes are identified. changes. The degenerated cells have pyknotic nuclei with increased intensity of cytoplasmic eosinophilia (Figure 6). If the interval between needling and biopsy is long enough, the displaced cells become necrotic or are completely removed by macrophages. -The cells are morphologically similar to the intraductal component.

-Immunostaining for cytokeratin (Figures 7 and 8) and CD68 may be helpful in distinguishing between DE and epithelioid histiocytes (Figures 3 and 6).

-Immunostaining for myoepithelial markers and high-molecular weight cytokeratin may be utilized when the intraductal component is a benign proliferation with preserved myoepithelial cells. ${ }^{46}$ However, the absence of staining for these markers does not preclude the 
possibility of DE.

-Sometimes the displaced epithelia are seen in lymphatic channels. There are even reports about the transfer of the displaced epithelia to the $\operatorname{lymph}_{36,37,47,48}$ nodes along the lymphatic channels. ${ }^{28,33,34,}$

-Fibrosis related to needling, and not a desmoplastic reaction around invasive carcinoma, is very extensive. Therefore, the displaced epithelia usually constitute a small fraction of an extensive reaction (Figure 3).

-Some displaced epithelial cells may show squamous metaplasia, resulting in its being mistaken as adenosquamous cell carcinoma.

Displacement of the epithelium to regional lymph nodes and even remote organs such as bone marrow is on record. ${ }^{37,}{ }^{49}$ Since most of these cases are misdiagnosed as metastasis by pathologists, the exact frequency of these findings cannot be determined. Some features useful for distinguishing between DE and real metastasis include:
- The displaced cells are usually in the form of isolated cells or small clusters.

- They are usually evenly distributed in the lymph node sinus and do not form expansile masses or nodules.

- They are accompanied by red blood cells, macrophages, and giant cells.

- The invasive component is very small (for instance, when we have a microinvasive carcinoma). - The grade of tumor and its type are less compatible with metastasis, e.g., a low-grade tumor or a papillary or mucinous carcinoma (in these situations, the likelihood of lymph node metastasis is very low, and if we see epithelial cells in lymph nodes, it should be interpreted cautiously).

- The biomarker results (ER, PR, and HER2) are different from the primary tumor.

- The tumor is morphologically different from the invasive carcinoma.

-DE is evident in lymphatic channels of the breast tissue

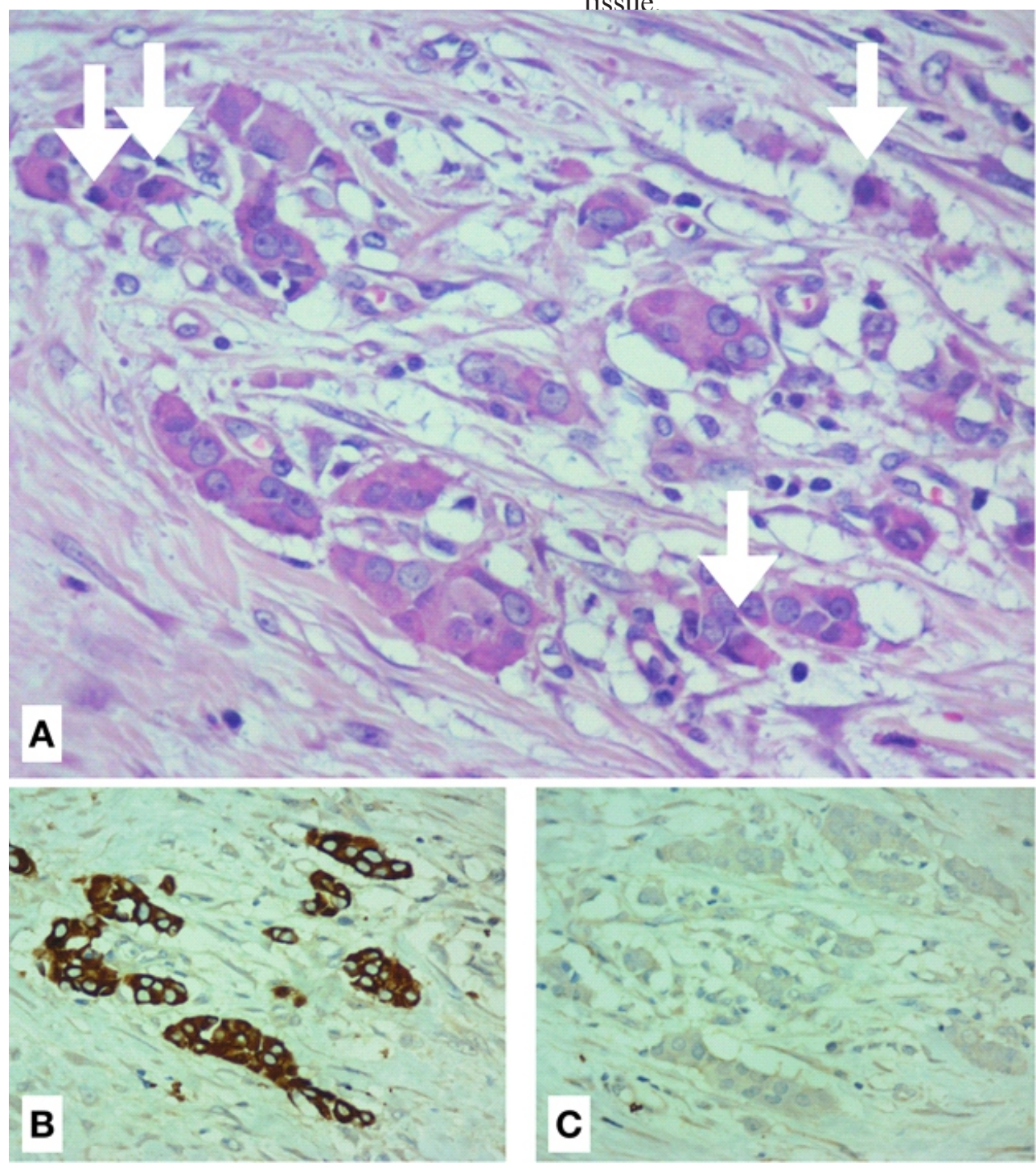

Figure 6. A. Displaced epithelium: some cells show degenerative changes characterized by pyknotic nuclei and increased eosinophilia of cytoplasm (white arrows); B. The displaced epithelium is highlighted by cytokeratin AE1/AE3; C. No staining for P63. 


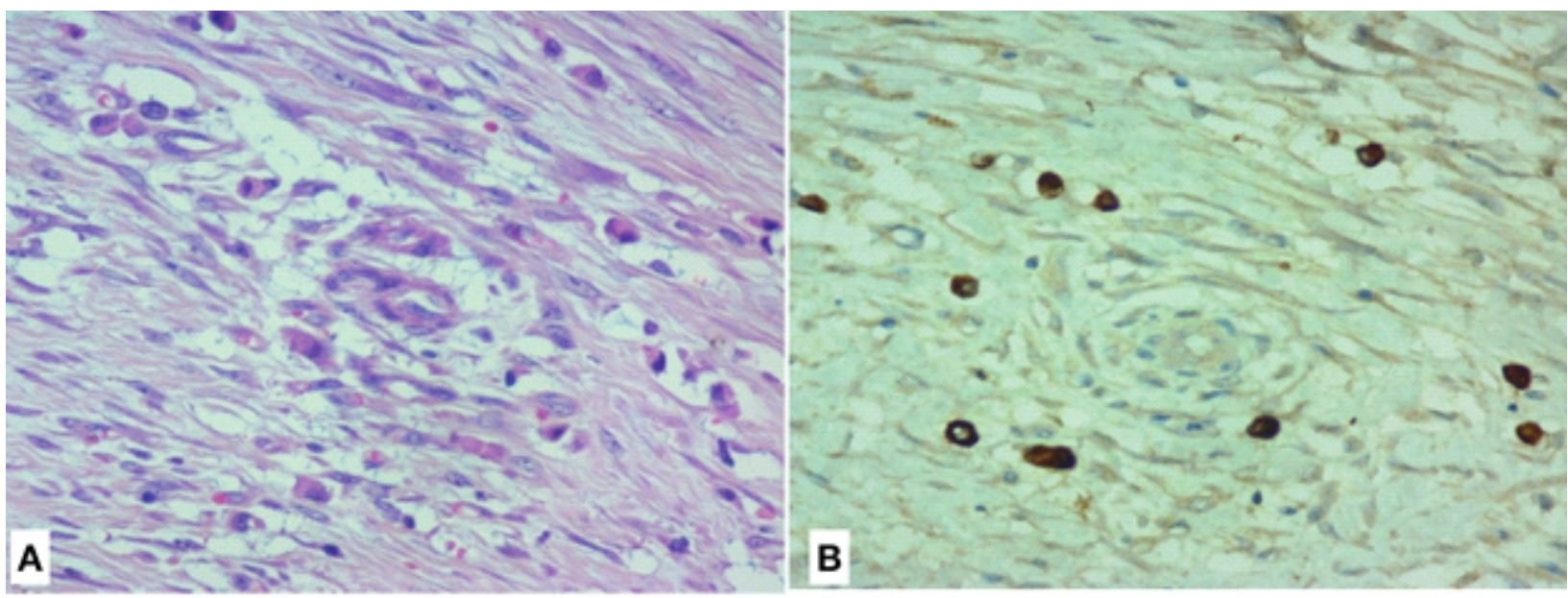

Figure 7. A. Scattered displaced epithelial cells are seen with marked degenerative changes. The degenerated cells have hyperchromatic pyknotic nuclei and densely eosinophilic cytoplasm; B. Because of the dispersion of displaced cells and degenerative changes, the epithelial nature of cells can be overlooked. In these situations, immunostaining for cytokeratin may be helpful in elucidating the nature of degenerated cells.

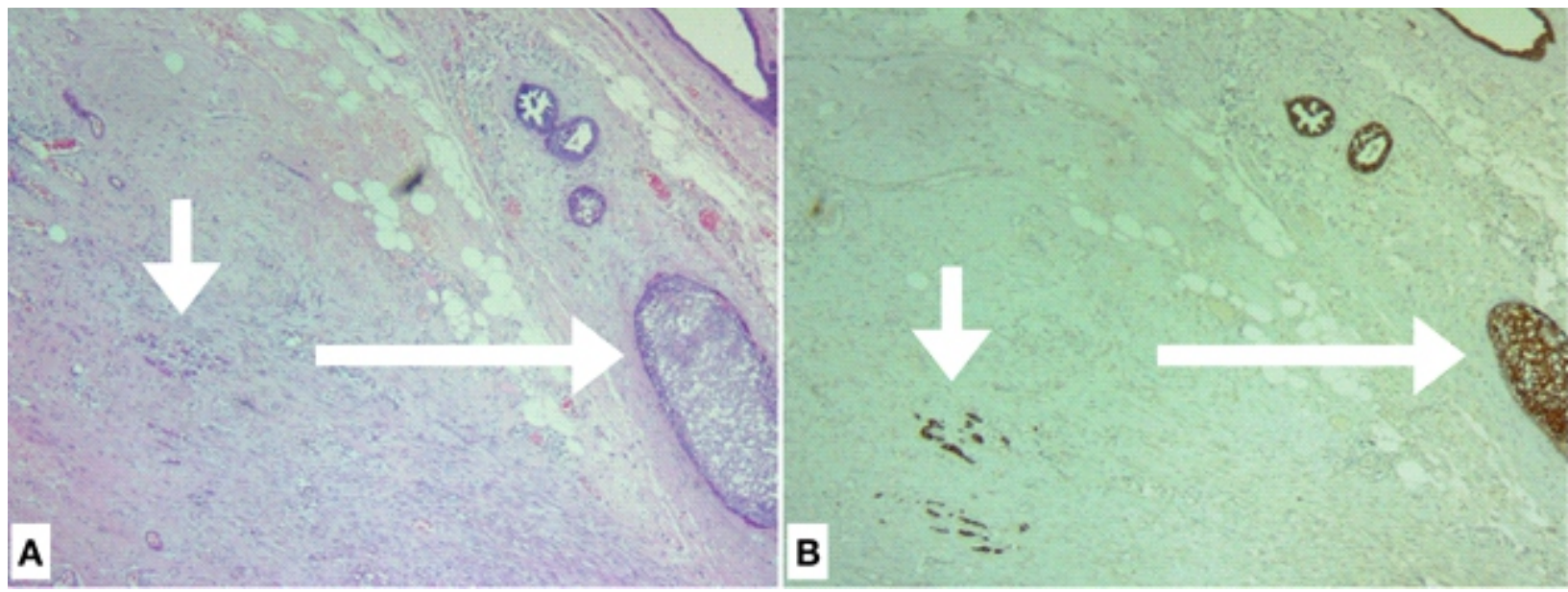

Figure 8. A. An atypical intraductal proliferation (the long arrow) and displaced epithelium (the short arrow) are depicted. Note the needle track features around the displaced epithelium (H\&E stain, $\times 40)$; B. Cytokeratin AE1/AE3 staining confirms the epithelial nature of the displaced epithelium (the short arrow). Cytokeratin also highlights the intraductal component (the long arrow) (magnification $\times 40$ ).

\section{Discussion}

Displacement of epithelium often occurs after needle biopsy of a breast lesion. Any epithelial cell can be displaced, including benign intraductal proliferations, in situ carcinoma, and invasive carcinoma. ${ }^{10}$ The major diagnostic problem is related to the displacement of intraductal proliferative cells (both benign and malignant) to the stroma or lymphatic channels, which results in misdiagnosis as an infiltrating tumor. ${ }^{8}$ Displacement of an invasive carcinoma along the needle track usually poses no diagnostic problem for the histopathologist. Its clinical significance has been discussed elsewhere in the manuscript. Occasionally, the displaced epithelium, dislodged into the lymph-vascular channels, may be carried to the regional lymph node, resulting in detection of isolated tumor cells in sentinel lymph nodes. ${ }^{36,37,47}$

Diagnosis of DE may be a great challenge for pathologists. Sometimes, it is overcalled as invasive carcinoma.
According to previous studies, the incidence of tumor seeding and recurrence at the site of needle track is low relative to the frequency of displaced tumor cells at this site. ${ }^{50}$ This finding may be explained based on cancer stem cell theory and the characteristics of malignant tumors. All tumors have two basic components including parenchyma and stroma. The stroma is host-derived and crucial for the growth of neoplasms because it supplies blood and essential factors. In tumors, normal interactions between cells and extracellular matrix are altered and disrupted so that tumor cells can detach from each other easily. Tumor cells, as well as host-derived stromal cells, can secrete proteolytic enzymes that can degrade interstitial connective tissue, facilitating the movement of and, eventually, local invasion by tumor cells. ${ }^{51}$

During diagnostic procedures such as core needle biopsy or aspiration and excisional biopsy, tumor cells can be dislodged and displaced in needle track. Detached tumor cells can also enter lymphatic channels via these procedures and, at least theoretically, 
colonize other sites far from the main lesion. ${ }^{37,49}$ How can the low rate of local recurrence at biopsy site or lymph node metastasis be explained despite the presence of tumor cells in lymph nodes?

Cancer cells do not survive alone but recruit normal host-derived cells to serve as contributing members by producing tumor microenvironment. Tissue microenvironment is necessary for the growth of the tumor and also the development of other characteristics of malignancy such as invasion and metastasis. The cells that contribute to the production of tumor microenvironment are cancerassociated fibroblasts, angiogenic vascular cells, and infiltrating immune cells. ${ }^{52}$

Alternatively, according to cancer stem cell theory, all tumors contain a population of cells that show biologic properties similar to those of normal adult stem cells. These stem cells are responsible, if not crucial, for maintenance of malignant tumors. ${ }^{53,54}$ Moreover, like normal stem cells, they require a specialized microenvironment named "stem cell niche" for regulation and progression of their growth. It represents a dynamic compartment by means of which additional components including endothelial, immune, and stromal cells as well as soluble factors help develop the environment necessary for both self-renewal and differentiation of stem cells. ${ }^{52,55}$

Almost all tumors, even at early phases, release cancer cells into blood, but a clinically evident metastatic disease occurs after a long period of latency. This observation suggests that metastatic colonization is an inefficient process and that most cancer cells die in blood. The investigations that show circulating tumor cells outnumber the overt metastatic lesion support this observation. ${ }^{56}$

Disseminated tumor cells need both stem cells and specialized microenvironment to survive. Experimental studies have provided evidence that signals from primary tumor can result in the development of a microenvironment in a distant homing organ. Thus, the so-called "premetastatic niche" is provided before the arrival of circulating tumor cells.

The low frequency of needle track seeding or metastasis can be due to the absence of cancer stem cells or appropriate microenvironment in the new location. However, this proposal should be confirmed by further investigations.

Although the frequency of seeding in needle track is very low, it is a well-documented entity. ${ }^{26,29,57}$ The risk factors for the development of seeding in the track of breast needling were evaluated in a study by Santiago et $a l .{ }^{18}$ They showed that the major risk factors included grade 3 infiltrating ductal carcinomas, triple-negative carcinomas, use of noncoaxial needles, and multiple insertions. The frequency of seeding in this study was less than $0.2 \%$ ( 8 of 4010 core needle biopsies) and the mean time between core needle biopsy and development of seeding was 60.8 days.

Undoubtedly, a large number of cases of displaced epithelia are signed out as invasive carcinoma or metastasis by pathologists all over the world. Accordingly, the unexpectedly good prognosis in some cases of presumed invasive carcinoma with regional lymph node metastasis can be attributable to the overcalling of a noninvasive lesion. ${ }^{33,58,59}$

As conclusion, we should be aware of the possibility of epithelial displacement after needle aspiration or biopsy to differentiate dislodged epithelial cells from infiltrating tumor cells and lymphatic invasion. Degenerative alteration of neoplastic cell clusters and the absence of desmoplastic stroma around them indicate epithelial displacement.

\section{References}

1. Ito Y, Tomoda C, Uruno T, Takamura Y, Miya A, et al. Needle tract implantation of papillary thyroid carcinoma after fine-needle aspiration biopsy. World J Surg. 2005;29(12):1544-9.

2. Ito Y, Asahi S, Matsuzuka F, Nakamura Y, Amino $\mathrm{N}$, et al. Needle tract implantation of follicular neoplasm after fine-needle aspiration biopsy: report of a case. Thyroid. 2006;16(10):1059-62.

3. Volpe A, Kachura JR, Geddie WR, Evans AJ, Gharajeh A, et al. Techniques, safety and accuracy of sampling of renal tumors by fine needle aspiration and core biopsy. J Urol. 2007;178(2):379-86.

4. Stokes ME, Thompson D, Montoya EL, Weinstein MC, Winer EP, et al. Ten-year survival and cost following breast cancer recurrence: estimates from SEER-medicare data. Value Health. 2008;11(2):213-20.

5. Horn T, Seidl S, Gschwend JE, Kubler H. Implantation metastasis of prostate cancer in a suprapubic cystostomy tube needle tract. Prostate Cancer Prostatic Dis. 2010;13(3):292-4.

6. Scotti V, Di Cataldo V, Falchini M, Meattini I, Livi L, et al. Isolated chest wall implantation of non-small cell lung cancer after fine-needle aspiration: a case report and review of the literature. Tumori. 2012;98(5):126e-9e.

7. Carlin SP, Garcia-Botella A, Diez-Valladares L, Perez-Aguirre E, Ortega L, et al. Dissemination of hepatocellular carcinoma in subcutaeous tissue after fine needle aspiration cytology (FNAC). Hepatogastroenterology. 2013;60(128):1839-40.

8. International Breast Cancer Consensus C. Image-detected breast cancer: state of the art diagnosis and treatment. International Breast Cancer Consensus Conference. J Am Coll Surg. 2001;193(3):297-302.

9. Perry NM, Party EW. Quality assurance in the diagnosis of breast disease. EUSOMA Working Party. Eur J Cancer. 2001;37(2):159-72. 
10. Clarke-Pearson EM, Jacobson AF, Boolbol SK, Leitman IM, Friedmann P, et al. Quality assurance initiative at one institution for minimally invasive breast biopsy as the initial diagnostic technique. J Am Coll Surg. 2009;208(1):75-8.

11. Gutwein LG, Ang DN, Liu H, Marshall JK, Hochwald SN, et al. Utilization of minimally invasive breast biopsy for the evaluation of suspicious breast lesions. Am J Surg. 2011;202(2): 127-32.

12. Torous VF, Schnitt SJ, Collins LC. Benign breast lesions that mimic malignancy. Pathology. 2017;49(2):181-96.

13. Hoorntje LE, Schipper ME, Kaya A, Verkooijen HM, Klinkenbijl JG, et al. Tumour cell displacement after $14 \mathrm{G}$ breast biopsy. Eur J Surg Oncol. 2004;30(5):520-5.

14. Liebens F, Carly B, Cusumano P, Van Beveren $\mathrm{M}$, Beier $\mathrm{B}$, et al. Breast cancer seeding associated with core needle biopsies: a systematic review. Maturitas. 2009;62(2):113-23.

15. Chao C, Torosian MH, Boraas MC, Sigurdson ER, Hoffman JP, et al. Local recurrence of breast cancer in the stereotactic core needle biopsy site: case reports and review of the literature. Breast $\mathrm{J}$. 2001;7(2):124-7.

16. Cho E, Kim MH, Cha SH, Cho SH, Oh SJ, et al. Breast cancer cutaneous metastasis at core needle biopsy site. Ann Dermatol. 2010;22(2): 238-40.

17. Brenner RJ, Gordon LM. Malignant seeding following percutaneous breast biopsy: documentation with comprehensive imaging and clinical implications. Breast J. 2011;17(6):651-6.

18. Santiago L, Adrada BE, Huang ML, Wei W, Candelaria RP. Breast cancer neoplastic seeding in the setting of image-guided needle biopsies of the breast. Breast Cancer Res Treat. 2017; 166(1):29-39.

19. Ansari TZ, Zaidi AA, Parekh A, Iqbal O, Masood $\mathrm{N}$, et al. Factors influencing the opinion of individuals in determining tumour spread after biopsy. BMC Res Notes. 2011;4:548.

20. Youngson BJ, Cranor M, Rosen PP. Epithelial displacement in surgical breast specimens following needling procedures. Am J Surg Pathol. 1994;18(9):896-903.

21. Youngson BJ, Liberman L, Rosen PP. Displacement of carcinomatous epithelium in surgical breast specimens following stereotaxic core biopsy. Am J Clin Pathol. 1995;103(5): 598-602.

22. Diaz LK, Wiley EL, Venta LA. Are malignant cells displaced by large-gauge needle core biopsy of the breast? AJR Am J Roentgenol. 1999;173(5):1303-13.

23. Liberman L, Vuolo M, Dershaw DD, Morris EA, Abramson AF, et al. Epithelial displacement after stereotactic 11-gauge directional vacuum- assisted breast biopsy. AJR Am J Roentgenol. 1999;172(3):677-81.

24. Thurfjell MG, Jansson T, Nordgren H, Bergh J, Lindgren A, et al. Local breast cancer recurrence caused by mammographically guided punctures. Acta Radiol. 2000;41(5):435-40.

25. Douglas-Jones AG, Verghese A. Diagnostic difficulty arising from displaced epithelium after core biopsy in intracystic papillary lesions of the breast. J Clin Pathol. 2002;55(10):780-3.

26. Knight R, Horiuchi K, Parker SH, Ratzer ER, Fenoglio ME. Risk of needle-track seeding after diagnostic image-guided core needle biopsy in breast cancer. JSLS. 2002;6(3):207-9.

27. Nagi C, Bleiweiss I, Jaffer S. Epithelial displacement in breast lesions: a papillary phenomenon. Arch Pathol Lab Med. 2005; 129(11):1465-9.

28. Bleiweiss IJ, Nagi CS, Jaffer S. Axillary sentinel lymph nodes can be falsely positive due to iatrogenic displacement and transport of benign epithelial cells in patients with breast carcinoma. J Clin Oncol. 2006;24(13):2013-8.

29. Fitzal F, Sporn EP, Draxler W, Mittlbock M, Taucher S, et al. Preoperative core needle biopsy does not increase local recurrence rate in breast cancer patients. Breast Cancer Res Treat. 2006;97(1):9-15.

30. Phelan S, O'Doherty A, Hill A, Quinn CM. Epithelial displacement during breast needle core biopsy causes diagnostic difficulties in subsequent surgical excision specimens. J Clin Pathol. 2007;60(4):373-6.

31. Michalopoulos NV, Zagouri F, Sergentanis TN, Pararas N, Koulocheri D, et al. Needle tract seeding after vacuum-assisted breast biopsy. Acta Radiol. 2008;49(3):267-70.

32. Uematsu T, Kasami M. Risk of needle tract seeding of breast cancer: cytological results derived from core wash material. Breast Cancer Res Treat. 2008;110(1):51-5.

33. van Deurzen CH, Bult P, de Boer M, Koelemij R, van Hillegersberg $\mathrm{R}$, et al. Morphometry of isolated tumor cells in breast cancer sentinel lymph nodes: metastases or displacement? Am J Surg Pathol. 2009;33(1):106-10.

34. Koo JS, Jung WH, Kim H. Epithelial displacement into the lymphovascular space can be seen in breast core needle biopsy specimens. Am J Clin Pathol. 2010;133(5):781-7.

35. McLaughlin CS, Petrey C, Grant S, Ransdell JS, Reynolds C. Displaced epithelium after liposuction for gynecomastia. Int J Surg Pathol. 2011;19(4):510-3.

36. Tvedskov TF, Jensen MB, Kroman N, Balslev E. Iatrogenic displacement of tumor cells to the sentinel node after surgical excision in primary breast cancer. Breast Cancer Res Treat. 2012;131(1):223-9. 
37. Nayak A, Bleiweiss IJ. Iatrogenically false positive sentinel lymph nodes in breast cancer: Methods of recognition and evaluation. Semin Diagn Pathol. 2018;35(4):228-35.

38. Loughran CF, Keeling CR. Seeding of tumour cells following breast biopsy: a literature review. Br J Radiol. 2011;84(1006):869-74.

39. Pisano ED, Fajardo LL, Tsimikas J, Sneige N, Frable WJ, et al. Rate of insufficient samples for fine-needle aspiration for nonpalpable breast lesions in a multicenter clinical trial: The Radiologic Diagnostic Oncology Group 5 Study. The RDOG5 investigators. Cancer. 1998;82(4): 679-88.

40. Altomare V, Guerriero G, Giacomelli L, Battista $\mathrm{C}$, Carino R, et al. Management of nonpalpable breast lesions in a modern functional breast unit. Breast Cancer Res Treat. 2005;93(1):85-9.

41.Dhillon MS, Bradley SA, England DW. Mammotome biopsy: impact on preoperative diagnosis rate. Clin Radiol. 2006;61(3):276-81.

42. Liberman L, Hann LE, Dershaw DD, Morris EA, Abramson AF, et al. Mammographic findings after stereotactic 14-gauge vacuum biopsy. Radiology. 1997;203(2):343-7.

43. Stolier A, Skinner J, Levine EA. A prospective study of seeding of the skin after core biopsy of the breast. Am J Surg. 2000;180(2):104-7.

44. Boutin C, Rey F, Viallat JR. Prevention of malignant seeding after invasive diagnostic procedures in patients with pleural mesothelioma. A randomized trial of local radiotherapy. Chest. 1995;108(3):754-8.

45. Peters-Engl C, Konstantiniuk P, Tausch C, Haid A, Hoffmann B, et al. The impact of preoperative breast biopsy on the risk of sentinel lymph node metastases: analysis of 2502 cases from the Austrian Sentinel Node Biopsy Study Group. Br J Cancer. 2004;91(10):1782-6.

46. Yeh IT, Mies C. Application of immunohistochemistry to breast lesions. Arch Pathol Lab Med. 2008;132(3):349-58.

47. Diaz NM, Cox CE, Ebert M, Clark JD, Vrcel V, et al. Benign mechanical transport of breast epithelial cells to sentinel lymph nodes. Am J Surg Pathol. 2004;28(12):1641-5.

48. Tada K, Ogiya A, Kimura K, Morizono H, Iijima $\mathrm{K}$, et al. Ductal carcinoma in situ and sentinel lymph node metastasis in breast cancer. World $\mathrm{J}$ Surg Oncol. 2010;8:6.

49. Shyamala K, Girish HC, Murgod S. Risk of tumor cell seeding through biopsy and aspiration cytology. J Int Soc Prev Community Dent. 2014;4(1):5-11.

50. Allawi Z, Cuzick J, Baum M, investigators AL. Does trauma or an intercurrent surgical intervention lead to a short-term increase in breast cancer recurrence rates? Ann Oncol. 2012;23(4):866-9.
51. Hanahan D, Coussens LM. Accessories to the crime: functions of cells recruited to the tumor microenvironment. Cancer Cell. 2012;21(3): 309-22.

52. Decker AM, Cackowski FC, Jung Y, Taichman RS. Biochemical Changes in the Niche Following Tumor Cell Invasion. J Cell Biochem. 2017;118(8):1956-64.

53. Jones DL, Wagers AJ. No place like home: anatomy and function of the stem cell niche. Nat Rev Mol Cell Biol. 2008;9(1):11-21.

54. Huch M, Rawlins EL. Cancer: Tumours build their niche. Nature. 2017;545(7654):292-3.

55. Melzer $\mathrm{C}$, von der Ohe J, Lehnert $\mathrm{H}$, Ungefroren $\mathrm{H}$, Hass R. Cancer stem cell niche models and contribution by mesenchymal stroma/stem cells. Mol Cancer. 2017;16(1):28.

56. Massague J, Obenauf AC. Metastatic colonization by circulating tumour cells. Nature. 2016; 529(7586):298-306.

57.Kopans DB, Gallagher WJ, Swann CA, McCarthy KA, White G, et al. Does preoperative needle localization lead to an increase in local breast cancer recurrence? Radiology. 1988; 167(3):667-8.

58. Giuliano AE, Hawes D, Ballman KV, Whitworth $\mathrm{PW}$, Blumencranz PW, et al. Association of occult metastases in sentinel lymph nodes and bone marrow with survival among women with early-stage invasive breast cancer. JAMA. 2011;306(4):385-93.

59. Weaver DL, Ashikaga T, Krag DN, Skelly JM, Anderson SJ, et al. Effect of occult metastases on survival in node-negative breast cancer. N Engl J Med. 2011;364(5):412-21. 